\title{
Palinologia de espécies de Gesneriaceae Rich. \& Juss. ocorrentes no estado do Rio de Janeiro, Brasil
}

\author{
Ana Carolina da Silva Fourny ${ }^{1,2}$, Cláudia Barbieri Ferreira Mendonça ${ }^{1,2}$, \\ Thereza Cristina Costa Lopes ${ }^{1}$ e Vania Gonçalves-Esteves ${ }^{1,2,3}$
}

Recebido em 19/11/2009. Aceito em 22/06/2010

RESUMO - (Palinologia de espécies de Gesneriaceae Rich. \& Juss. ocorrentes no estado do Rio de Janeiro, Brasil). Foi realizado um estudo palinológico de 21 espécies da família Gesneriaceae reunidas em seis gêneros e três tribos: tribo Beslerieae - Besleria L. (4 spp.); tribo Episcieae - Codonanthe (Mart.) Hanst. (3 spp.), Nematanthus Schrad. (5 spp); tribo Sinningieae - Paliavana Vand. (1 sp.), Sinningia Nees (6 spp.) e Vanhouttea Lem. (2 spp.) ocorrentes no Estado do Rio de Janeiro, Brasil. Objetivou-se caracterizar e ampliar os dados morfológicos da família, em nível genérico ou específico, contribuindo assim, para uma delimitação mais precisa dos táxons. Os grãos de pólen foram acetolisados, medidos, descritos e ilustrados sob microscopia de luz. Para observar detalhes da superfície e abertura, grãos de pólen não acetolisados foram analisados em microscópio eletrônico de varredura (MEV). Os grãos de pólen das espécies estudadas variaram de pequenos a médios, suboblatos a prolatos; apresentaram cólporos ou colpos e o número de aberturas foi constante para todas as espécies analisadas (3-aperturados). A ornamentação da sexina variou entre escabrada, perfurada, rugulada, microrreticulada e reticulada. Os resultados mostraram que a morfologia polínica é bem definida entre as espécies estudadas, variou dentro e entre as tribos e gêneros, podendo ser usada para identificar os táxons e sustentar o caráter euripalinológico de Gesneriaceae.

Palavras-chave: Palinotaxonomia, pólen, Lamiales, Floresta Atlântica

ABSTRACT - (Palynology of Gesneriaceae Rich. \& Juss. species from Rio de Janeiro state, Brazil). This work deals with the study of pollen of 21 species from the family Gesneriaceae found in six genera, divided into three tribes: Beslerieae tribe - Besleria L. (4 spp.) Episcieae tribe - Codonanthe (Mart.) Hanst. (3 spp.) Nematanthus Schrad. (5 spp); Sinningieae tribe - Paliavana Vand. (1 sp.), Sinningia Nees (6 spp.) and Vanhouttea Lem. (2 spp.), occurring in Rio de Janeiro state, Brazil. We aim to characterize and expand the morphological data of the family, at the general or specific level, thus contributing to a more precise delimitation of taxa. The pollen grains were acetolysed, measured, described and illustrated using light microscopy. To see details of the surface and opening, non-acetolysed pollen grains were examined with a scanning electron microscope (SEM). The pollen grains of the species studied ranged from small to medium, suboblate to prolate; they had colpores or colpes and the number of openings was constant for all species (3-aperture). Ornamentation of the sexine ranged from scabrous to perforated, rugulate, microrreticulate and reticulated. The results showed that pollen morphology is well defined for the species studied; it varied within and between tribes and genera, can be used to identify taxa and maintains the eurypalynological character of the family Gesneriaceae.

Key words: Palynotaxonomy, pollen, Lamiales, Atlantic rain forest

\section{Introdução}

A família Gesneriaceae Rich. \& Juss. possui cerca de 150 gêneros e 3700 espécies, subdivididas em três subfamílias, com distribuição ampla nas zonas tropicais do mundo, e mais raramente em zonas temperadas (Wiehler 1983; Burtt \& Wiehler 1995). De acordo com Wiehler (1983), Gesneriaceae está subordinada à ordem Scrophulariales. Na classificação atual, segundo a proposta do APG III (2009), a família está posicionada na ordem Lamiales e forma o clado das Asterideas.

O Brasil trata-se, provavelmente, de um centro de diversidade secundário da subfamília neotropical Gesnerioideae, com aproximadamente 23 gêneros reunindo 220 espécies, apresentando importante concentração e elevado endemismo na região Sudeste, ocorrendo principalmente na Floresta Atlântica brasileira (Chautems 1988; Chautems 1991; Chautems \& Matsuoka 2003). O Estado do Rio de Janeiro abriga alta diversidade da família (Chautems com. pess.) e é considerado um dos maiores centros de endemismo de espécies da fauna e flora do país (Bergallo et al. 2000; Rocha et al. 2003), sendo reconhecidas aproximadamente 55 espécies subordina- das a sete gêneros, pertencentes a quatro tribos, sendo 20 espécies, aproximadamente, consideradas endêmicas (Skog \& Boggan, 2007).

Muitas análises baseadas em dados moleculares foram realizadas por diversos autores entre eles: Smith (1996; 2000), Smith et al. (1997), Albach et al. (2001); Zimmer et al. (2002); Perret et al. (2003) e Clark et al. (2006), que confirmam o monofiletismo da família, da subfamília Gesnerioideae e das tribos amostradas neste trabalho, sugerindo modificações no posicionamento de algumas espécies e gêneros. No entanto, estudos publicados sobre o grão de pólen de Gesneriaceae são basicamente morfológicos, com raras menções de suas aplicações taxonômicas, embora a forma e a estrutura dos grãos de pólen constituam um novo e importante caráter diagnóstico da família que pode vir a auxiliar a delimitação taxonômica dos gêneros (Fritze \& William 1988).

O presente trabalho visa à caracterização morfopolínica e a identificação de caracteres de valor diagnóstico que contribuam para a taxonomia da família em nível genérico e/ou específico, com o objetivo de também auxiliar à taxonomia e filogenia do grupo.

\footnotetext{
1 Universidade Federal do Rio de Janeiro, Pós-Graduação em Botânica, Museu Nacional, São Cristóvão, RJ, Brasil

2 Universidade Federal do Rio de Janeiro, Departamento de Botânica, Museu Nacional, São Cristóvão, RJ, Brasil

3 Autor para correspondência: esteves.vr@gmail.com
} 


\section{Material e métodos}

Foram estudados os grãos de pólen de 21 espécies subordinadas a seis gêneros e três tribos de Gesneriaceae ocorrentes no Estado do Rio de Janeiro. Este universo não corresponde à totalidade das espécies registradas para o Estado (cerca de 55 espécies distribuídas em sete gêneros e quatro tribos). A falta de material fértil nos herbários visitados foi determinante para a escolha das espécies associada à decisão de se caracterizar palinologicamente o maior número de representantes dos gêneros e das tribos.

O material botânico utilizado constou de flores em antese e/ou botões florais retirados de exsicatas depositadas em herbários do Estado do Rio de Janeiro, cujas siglas estão relacionadas de acordo com o Index Herbariorum (Holmgren et al. 1990).

Para cada espécie estudada foi escolhido um espécime considerado padrão, indicado por asterisco $(*)$ junto ao nome do coletor e três espécimes para comparação a fim de confirmar os resultados obtidos. Para a escolha do material padrão, foram adotados os seguintes critérios: ter sido coletado no Estado do Rio de Janeiro, preferencialmente, e ter sido identificado por especialista da família. As lâminas utilizadas no estudo foram depositadas na Palinoteca do Laboratório de Palinologia Álvaro Xavier Moreira, do Departamento de Botânica do Museu Nacional/UFRJ.

Material utilizado:

Besleria longimucronata Hoehne - BRASIL. Rio de Janeiro: Mangaratiba, trilha para Lagoa Seca, *T.C.C. Lopes 41, 13/X/2003 (RUSU); Rio de Janeiro: Mangaratiba, trilha para Lagoa Seca, T.C.C. Lopes 40, 13/X/2003 (RUSU); Rio de Janeiro: Paraty, G. Martinelli e J. Orleans 13467, 11/ IX/1990 (RB); Rio de Janeiro: Paraty, M.C. Marques 426, 10/VIII/1994 (RB). Besleria macahensis Brade - Rio de Janeiro: Macaé, Distrito do Sana, cachoeira do Sana, *M.G. Bovini 2102, 28/XI/2001 (RB); Rio de Janeiro: Trajano de Moraes, E. Santos 2.212, B. Faster, 1227, 11/XII/1965 (R). Besleria melancholica (Vell.) C.V. Morton - Rio de Janeiro: Rio de Janeiro, Floresta da Tijuca, *G.F.J. Pabst. 7419, 08/XII/1962 (HB); Rio de Janeiro: Rio de Janeiro, Tijuca, Gruta et al. s/n, 11/XI/1948 (R49878); Rio de Janeiro: Rio de Janeiro, Estrada do Sumaré, E. Pereira s/n, 05/X/1965 (HB13182); Rio de Janeiro: Rio de Janeiro, Estrada do Cristo, E. Pereira e Duarte s/n, 30/X/1951 (HB7149). Besleria umbrosa Mart.- Rio de Janeiro: Rio de Janeiro, Rodovia Rio-Petrópolis, * G.F.J. Pabst. 7376, 11/IX/1963 (HB); Rio de Janeiro: Petrópolis, Serra da Estrela, Glaziou s/n, 28/VIII/1982 (R11055); Rio de Janeiro: Petrópolis, Serra da Estrela, A.C.Brade $s / n$., 28/VII/1929 (R 20945); Rio de Janeiro: Rio de Janeiro, Manguinhos, $A$. Lutz 315, 07/XII/1982 (R). Codonanthe carnosa (Gardner) Hanst. - Rio de Janeiro: Teresópolis, *A.C. Brade s/n., 14/X/1949 (R96970); Rio de Janeiro: Rio de Janeiro, Morro Queimado, A.P. Duarte 5297, 20/IX/1960 (R); Rio de Janeiro: Rio de Janeiro, Morro Queimado, A.P. Duarte 5297, 20/IX/1960 (HB). Codonanthe devosiana Lem. - Rio de Janeiro: Mangaratiba, Reserva Rio das Pedras, Margem do Rio Grande, *T.C.C. Lopes 55 , 14/X/2003 (RUSU); Santa Catarina: Florianópolis, Canavieiras, Ilha de Santa Catarina, Klein e Bresolin 5399, 04/VIII/1964 (R); Rio de Janeiro: Paraty, Konno, T. 209, 01/VII/1993 (RB); Rio de Janeiro: Petrópolis, Serra dos Órgãos, E. Pereira 634, 26/X/1959 (RB). Codonanthe gracilis (Mart.) Hanst. - Rio de Janeiro: Mangaratiba, Reserva Rio das Pedras, Margem do Rio Grande, *T.C.C. Lopes 52, 14/X/2003 (RUSU); Rio de Janeiro: Rio de Janeiro, Recreio dos Bandeirantes, A.P. Duarte 6239, 19/IV/1983 (RB); Rio de Janeiro: Paraty, APA - Cairuçú, B.A. Moreira 18, 19/X/1993 (RB). Nematanthus brasiliensis (Vell.) Chautems - Rio de Janeiro: Mangaratiba, Reserva Rio das Pedras, Margem do Rio Pequeno, *J.M.A. Braga 3430, 17/VIII/1996 (RB). Nematanthus crassifolius (Schott) Wiehler - Rio de Janeiro: Guapimirim, *J.A. Lira Neto e M.G. Bovini s/n., 16/VIII/1995 (RUSU 5900); Rio de Janeiro: Angra dos Reis, D. Araújo 3999 e N.C. Maciel, 18/IV/1983 (GUA); Rio de Janeiro: Guapimirim, J.M.A. Braga 524, 18/VIII/1993 (RUSU). Nematanthus fissus (Vell.) L.E. Skog - Rio de Janeiro: Paraty, Rodovia Rio-Santos (BR 101), * L.C. Giordano 1764 et al., 23/XI1/1994 (RB); Rio de Janeiro: Paraty, APA - Cairuçú, Praia da Ponta Negra, C. Duarte 40, 12/04/1994 (RB); Rio de Janeiro: Angra dos Reis, mata de restinga, praia do Sul, D.S. Pedrosa 1121 e H.Q. Boudet 929, 13/ VI/ 1984 (GUA). Nematanthus fluminensis (Vell.) Fritsch - Rio de Janeiro: Paraty, Enseada de Paraty Mirim, Ilha da Cotia, *T. Konno 418 et al., 13/VI/1994 (RB); Rio de Janeiro: Paraty, Enseada de Paraty Mirim, C.B. Moreira 10 et al., 16/V/1995 (RB); Rio de Janeiro: Angra dos Reis, Z.A. Trinta 875 e E. Fromm 1951, 19/IX/1964 (HB); Rio de Janeiro: Paraty, APA-Cairuçu:
Parati-mirim na trilha para Laranjeiras (Pedra Azul), C.B, Moreira 10 16/V/1995 (RB). Nematanthus hirtellus (Schott) Wiehler - Rio de Janeiro: Mangaratiba, Reserva Rio das Pedras, Trilha Para Lagoa Seca, *T.C.C. Lopes 43, 13/X/2003 (RUSU); Rio de Janeiro: Itatiaia, Mauá, Schwacke s/n, XI/1890 (R 20928); Rio de Janeiro: Tinguá, Boa Esperança, L. Emygdio $s / n, 08 / \mathrm{I} / 1957$ (HB103948); Rio de Janeiro: Duque de Caxias, I.C. Santana et al. s/n, 19/I/1997 (HB81850). Paliavana prasinata (Ker Gawl.) Benth. et Hook.f. - Rio de Janeiro: Mangaratiba, Poço Rio Grande, *J.M.A.Braga 3942, 23/III/1997 (RUSU); Rio de Janeiro: Angra dos Reis, Ilha Grande, F. Pinheiro et al. 716, 28/I/2001 (HB); Rio de Janeiro: Rio de Janeiro, Gávea, Morro Dois Irmãos, L. Emygdio 425, 05/VI/1946 (R); Rio de Janeiro: Angra dos Reis, F. Pinheiro 659 et al., 17/XII/2000 (HB). Sinningia bulbosa (Ker Gawl.) Wiehler - Rio de Janeiro: Rio de Janeiro, Barra da Tijuca, Morro do Focinho do Cavalo, * C.A.L. de Oliveira 1923, 01/X/2001 (GUA); Rio de Janeiro: Rio de Janeiro, Praia de Grumari, H.F. Martins 167, 22/II/1960 (GUA); Rio de Janeiro: Rio de Janeiro, Barra da Tijuca, Margem do Canal de Marapendi, J.M.A. Braga 7102, 23/IV/2002 (RB). Sinningia douglasii (Lindl.) Chautems - Rio de Janeiro: Teresópolis, Campo das Antas, *Rizzini 272, 14/VII/1948 (RB); Rio de Janeiro: Petrópolis, Brade 18687 et Apparicio, 29/X/1949 (RB); Rio de Janeiro: Petrópolis, D. Sucre 3993 et $P$. I. S. Braga, 02/XI/1968 (RB); Minas Gerais: Belo Horizonte, H.S. Irwuin et al. s/n., 11/II/1968 (HB 61590). Sinningia gigantifolia Chautems - Rio de Janeiro: Petrópolis, Serra dos Órgãos, *Carauta s/n., 28/III/1971 (GUA 8118); Rio de Janeiro: Itatiaia, M.V. Alves 660 et al., 18/II/1992 (GUA). Sinningia guttata Lindl. - Rio de Janeiro: Rio de Janeiro, Parque Municipal da Prainha, *J.M.A.Braga 7281 et al., 13/XI/2003 (RB); Rio de Janeiro: Rio de Janeiro, Andaraí, J.G. Kuhlman 6056 (RB); Rio de Janeiro: Rio de Janeiro, Parque Nacional da Tijuca, Grajaú, D. Sucre 8825, 14/IV/1972 (RB); Rio de Janeiro: Saquarema, Serra da Pedra Branca, C. Farney 132, 15/V/1982 (RB). Sinningia lateritia (Lindl.) Chautems - Rio de Janeiro: Petrópolis, Distrito de Araras, Morro da Cuca, *R. Ribeiro 2186, 02/III/1994 (GUA). Vanhouttea calcarata Lem. - Rio de Janeiro: Petrópolis, Vale do Rio Bonfim, *C.E.M. Fonseca 4, 10/VII/1988 (GUA). Vanhouttea lanata Fritsch - Rio de Janeiro: Teresópolis, Distrito de Nhunguaçu, Fazenda da Varginha, ${ }^{*} R$. Ribeiro 788 et al., 02/IV/1986 (GUA).

O material polínico foi preparado segundo o método acetolítico de Erdtman (1952), com as modificações propostas por Melhem et al. (2003), visando à observação em microscopia de luz.

Do material padrão foram tomadas, aleatoriamente, 25 medidas do diâmetro polar (DP) e diâmetro equatorial (DE) dos grãos de pólen em vista equatorial e 10 medidas do diâmetro equatorial em vista polar (DEVP) e o lado do apocolpo (LA), em vista polar, distribuídas em um mínimo de três lâminas. Foi realizado o tratamento estatístico calculando-se a média aritmética (x), desvio padrão da amostra (s), desvio da média ( $\mathrm{s}$ ), o coeficiente de variabilidade (CV\%), o intervalo de confiança a $95 \%$ e a faixa de variação. Para os demais caracteres tais como, as aberturas, as camadas da exina e os diâmetros do material de comparação, foram mensurados, aleatoriamente, 10 grãos de pólen distribuídos, no mínimo, em três lâminas e calculada a média aritmética (Salgado-Labouriau 1973).

A terminologia adotada foi de Punt et al. (2007) levando-se em consideração o tamanho, a forma, o número de aberturas e o padrão de ornamentação da sexina.

As fotomicrografias dos grãos de pólen em microscopia de luz foram realizadas com auxílio de câmera digital Sony Cyber-shot DSC-W7 acoplada ao microscópio Zeiss Axiostar Plus. Visando a análise sob microscopia eletrônica de varredura (MEV), grãos de pólen não acetolisados, foram espalhados pela superfície de fitas dupla-face de carbono, que recobrem suportes de alumínio, devidamente numerados. As amostras foram transferidas para uma bomba de vácuo e metalizadas com uma fina camada de ouro paládio (ca. 150 ângstrons de espessura) sendo, posteriormente, analisadas em aparelho ZEISS DS M960, pertencente ao Laboratório de Ultraestrutura Celular/Instituto de Biofísica (UFRJ) e JEOL JSM-5800, pertencente ao Departamento de Invertebrados do Museu Nacional/UFRJ.

\section{Resultados}

Tribo Beslerieae (Fig. 1-9)

1. Besleria L. - Besleria longimucronata Hoehne (Fig. 1-2), Besleria macahensis Brade (Fig. 3-4), Besleria melan- 
cholica (Vell.) C.V. Morton (Fig. 5-6), Besleria umbrosa Mart. (Fig. 7-9).

Grãos de pólen médios apenas em B. macahensis e pequenos na maioria das espécies, isopolares, prolatos (Tab. 1,2), 3-colporados apenas em B. umbrosa e 3-colpados nas demais espécies estudadas (Tab. 1), âmbito subtriangular em B. longimucronata e B. melancholica (Fig. 1), subcircular em B. umbrosa e circular em B. macahensis, área polar pequena em $B$. longimucronata e grande nas demais espécies (Tab. 3), superfície escabrada, perfurada ou rugulada (Tab.1).

Aberturas: 3 cólporos apenas em B. umbrosa (Fig. 7, 8) ou 3 colpos nas demais espécies estudadas (Fig. 3), colpos longos apenas em $B$. longimucronata e curtos nas demais espécies (Tab. 1, 2), com margem espessa em todas as espécies, aparentando ser sincolpados em B. longimucronata e $B$. melancholica (Fig. 1). Os menores valores no comprimento e na largura do colpo foram encontrados em B. melancholica e os maiores em B. umbrosa (Tab. 2). Sob $\mathrm{MEV}$, observa-se membrana conspicuamente granulada recobrindo a abertura, em todas as espécies estudadas (Fig. $5,8)$. Na espécie colporada, a endoabertura foi considerada ligeiramente lolongada (Tab. 1, 2).

Exina: pouco espessa, sexina tectado-perfurada nas espécies $B$. longimucronata e $B$. umbrosa, com ondulações no teto apenas na segunda espécie (Fig. 2, 9), escabrada com perfurações em B. macahensis (Fig. 4) e levemente rugulada com perfurações em B. melancholica (Fig. 6). A sexina é sempre mais espessa do que a nexina sendo os maiores valores de sexina encontrados em B. melancholica (Tab. 3).

Comentários: $B$. macahensis foi pouco frequente nos herbários consultados, só tendo sido encontrado um espécime para comparar com material padrão. Os espécimes usados para comparação das outras espécies analisadas ficaram, na sua maioria, fora do intervalo de confiança e dentro dos limites da faixa de variação, a forma se manteve constante quando comparada com a do respectivo material padrão (Tab. 4).

Tribo Episcieae (Fig. 10-34)

1. Codonanthe (Mart.) Hanst. (Fig. 10-20) - Codonanthe carnosa (Gardner) Hanst. (Fig. 10-13), Codonanthe devosiana Lem. (Fig. 14-16), Codonanthe gracilis (Mart.) Hanst. (Fig. 17-20).

Grãos de pólen médios, isopolares, prolato-esferoidais em $C$. devosiana, suboblatos em $C$. gracilis e oblatoesferoidais em C. carnosa, 3-colporados (Tab. 1, 2), âmbito subcircular apenas em C. gracilis (Fig. 17) e subtriangular nas demais espécies (Fig. 10), área polar pequena em todas as espécies estudadas (Tab. 3), superfície microrreticulada (Tab. 1).

Abertura: 3 cólporos, colpos longos (Tab. 1), endoabertura circular em C. devosiana, lolongada em C. carnosa (Fig. 12) e ligeiramente lolongada em C. gracilis (Fig. 18) (Tab. 2). Sob $\mathrm{MEV}$, observa-se que a membrana que recobre a abertura é densamente ornamentada em todas as espécies estudadas (Fig. 15).
Exina: microrreticulada com perfurações (Fig. 13, 16, 20), microrretículos simplescolumelados, com variação no tamanho e forma dos lumens (Fig. 16, 20). Sob MEV, é possível observar que em $C$. devosiana os retículos diminuem na região do apocolpo, e a ornamentação é quase psilada com perfurações esparsas (Fig. 14), enquanto nas demais espécies o padrão de ornamentação se manteve constante (Fig. 11). Sexina tão espessa quanto a nexina em $C$. carnosa e mais espessa do que a nexina nas demais espécies. A sexina mais espessa foi encontrada em C. gracilis (Tab. 3).

Comentários: Os espécimes usados para comparação dos resultados ficaram fora do intervalo de confiança, porém dentro da faixa de variação na maioria das espécies quando comparados com o respectivo material padrão (Tab. 4).

2. Nematanthus Schrad. (Fig. 21-34) - Nematanthus brasiliensis (Vell.) Chautems (Fig. 21-23), Nematanthus crassifolius (Schott) Wiehler (Fig. 24-25), Nematanthus fissus (Vell.) L.E. Skog (Fig. 26-28), Nematanthus fluminensis (Vell.) Fritsch (Fig. 29-31), Nematanthus hirtellus (Schott) Wiehler (Fig. 32-34).

Grãos de pólen médios, oblato-esferoidais em N. crassifolius e $N$. fissus, prolato-esferoidais em $N$. brasiliensis e $N$. fluminensis e subprolatos apenas em $N$. hirtellus (Tab. 1); 3-colpados em N. fluminensis e N. hirtellus (Fig. 30, 33), 3-colporados nas demais espécies (Fig. 22, 25, 27), âmbito subtriangular em $N$. fissus e $N$. fluminensis (Fig. 26), subcircular nas demais espécies (Fig. 21, 32) e área polar muito pequena em $N$. brasiliensis e $N$. fluminensis e pequena nas demais espécies (Tab. 3), superfície heterorreticulada.

Abertura: 3-colpados ou 3-colporados, colpos muito longos e largos em $N$. brasiliensis e $N$. fluminensis e longos nas demais espécies (Tab. 1, 2), sendo os maiores valores de comprimento e largura encontrados nas espécies $N$. crassifolius e $N$. fissus e os menores valores na espécie $N$. hirtellus (Tab. 2), no caso das espécies 3-colporadas a endoabertura mostrou-se lalongada em $N$. crassifolius, lolongada em $N$. brasiliensis e levemente lolongada em N. fissus (Tab. 2). Sob MEV, observa-se que o colpo apresenta uma margem larga psilada com perfurações em $N$. crassifolius, $N$. fissus e $N$. fluminensis (Fig. 28) e uma membrana apertural densamente ornamentada em todas as espécies estudadas (Fig. 24, 32).Exina: heterorreticulada (Tab. 1); retículos com forma e dimensões variáveis, formando lumens grandes, que diminuem de tamanho próximo à região apertural (Fig. 35) (Tab. 3), com perfurações na região do apocolpo. Em MEV é possível observar muros com muitas perfurações (Fig. 31), sinuosos na maioria das espécies estudadas (Fig. 23,28 ) e retos apenas em $N$. fluminensis e $N$. hirtellus (Fig. $31,34)$ e grânulos no interior dos lumens somente em $N$. fissus e $N$. fluminensis (Fig. 28, 31, 33). A sexina se mostrou mais espessa do que a nexina nas espécies $N$. fluminensis e $N$. hirtellus, menos espessa nas espécies $N$. brasiliensis e $N$. crassifolius e tão espessa quanto a nexina somente em N. fissus (Tab. 3). 

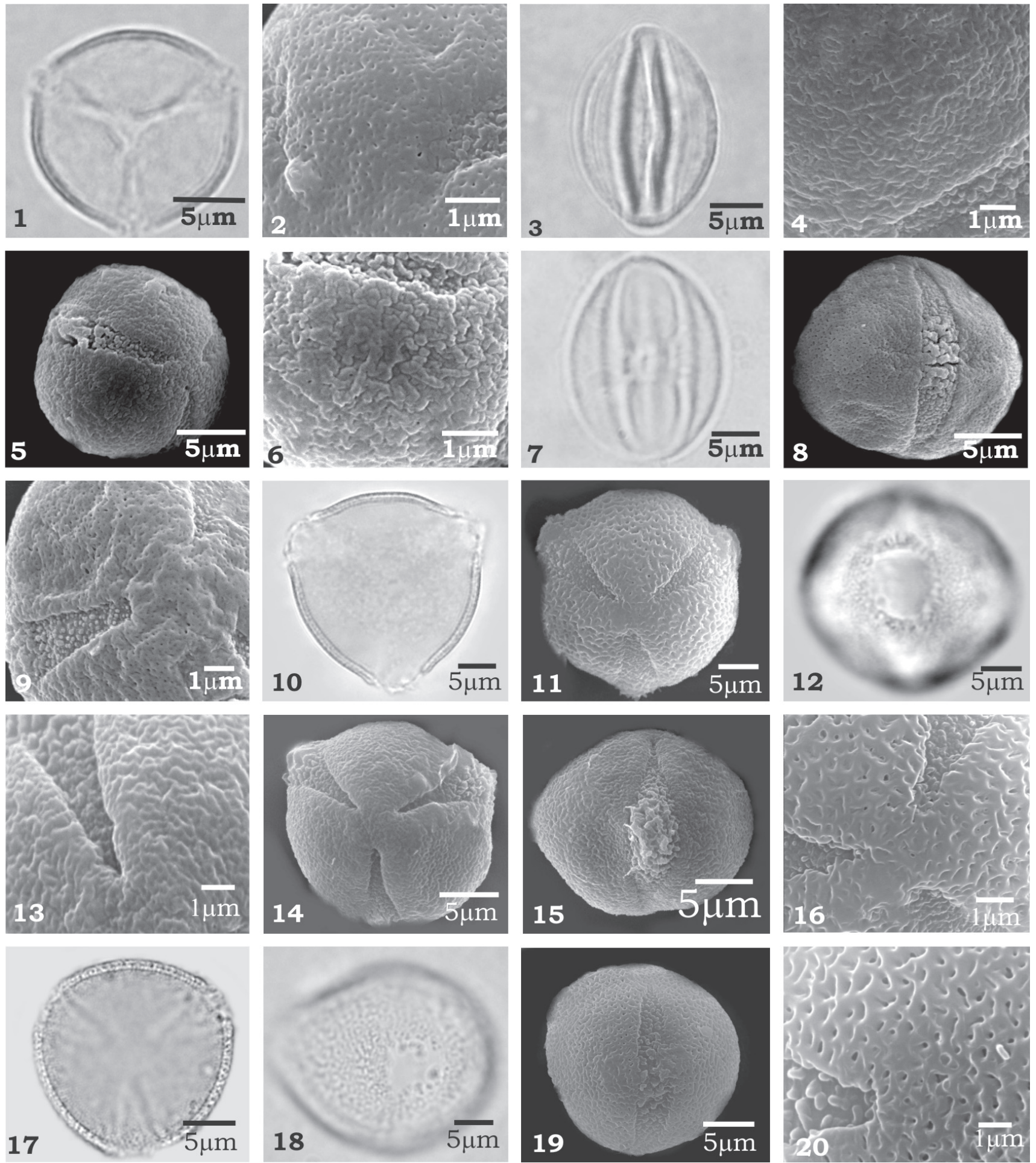

Figuras 1-20. Fotomicrografias e eletromicrografias dos grãos de pólen de Besleria L. e Codonanthe (Mart.) Hanst. 1-2. B. longimucronata Hoehne -1. vista polar: corte óptico; 2. superfície (MEV). 3-6. B. macahensis Brade - 3. abertura; 4. superfície (MEV); 5. vista geral (MEV); 6. superfície (MEV). 7-9. B. umbrosa Mart.7. abertura; 8. vista geral (MEV); 9. superfície (MEV). 10-13. C. carnosa (Gardner) Hanst.- 10. vista polar: corte óptico; 11. vista geral (MEV); 12. abertura; 13. superfície (MEV). 14-16. C. devosiana Lem.- 14. vista polar (MEV); 15. abertura (MEV); 16. superfície (MEV). 17-20. C. gracilis (Mart.) Hanst. - 17. vista polar: corte óptico; 18. abertura; 19. vista geral (MEV); 20. superfície (MEV). 
Comentários: Algumas espécies do gênero Nematanthus estão pouco representadas nos herbários consultados, minimizando a disponibilidade de materiais utilizados para comparação. Os espécimes usados para comparação dos resultados (Tab. 4) ficaram fora do intervalo de confiança e da faixa de variação quando comparados com o respectivo material padrão.

Tribo Sinningieae (Fig. 35-60)

1. Paliavana Vand. (Fig. 35-37) - Paliavana prasinata (Ker

Gawl.) Benth. et Hook.f. (Fig. 35-37).

Grãos de pólen médios, isopolares, subprolatos (Tab. 1), 3-colporados, âmbito subtriangular, área polar muito pequena (Tab. 3), superfície heterorreticulada (Fig. 37).

Abertura: 3-colporados, colpos muito longos, endoaber- tura lolongada (Tab. 1, 2). Sob MEV, observa-se colpo com membrana ornamentada, margem larga, psilada, endoabertura com membrana conspicuamente ornamentada (Fig. 36).

Exina: heterorreticulada, retículos formados por muros largos, retos, lumens pequenos, com forma e dimensões variáveis (Fig. 37). Sob MEV verifica-se que os lumens vão diminuindo à medida que se aproximam da abertura e a ornamentação na região do apocolpo é quase psilada com perfurações (Fig. 34). Sexina mais espessa que a nexina (Tab. 3).

Comentários: Nos espécimes usados para comparação dos resultados (Tab. 4) os valores do diâmetro polar ficaram dentro do intervalo de confiança e da faixa de variação quando comparados com o respectivo material padrão.

2. Sinningia Nees (Fig. 38-55) - Sinningia brasiliensis (Regel \& E. Schmidt) Wiehler \& Chautems (Fig. 38-40),

Tabela 1. Caracterização morfológica dos grãos de pólen das espécies de Gesneriaceae analisadas.

\begin{tabular}{|c|c|c|c|c|c|c|}
\hline Táxons & Tamanho & Forma & Abertura & Colpo & Endoabertura & Sexina \\
\hline Besleria longimucronata & pequeno & prolata & 3- colpos & longo & --- & perfurada \\
\hline Besleria macahensis & médio & prolata & 3- colpos & curto & --- & escabrada com perfuração \\
\hline Besleria melancholica & pequeno & prolata & 3- colpos & curto & --- & $\begin{array}{l}\text { levemente rugulada } \\
\text { com perfurações }\end{array}$ \\
\hline Besleria umbrosa & pequeno & prolata & 3- cólporos & curto & ligeiramente lolongada & $\begin{array}{l}\text { perfurada com } \\
\text { ondulações no teto }\end{array}$ \\
\hline Codonanthe carnosa & médio & oblato-esferoidal & 3-cólporos & longo & lolongada & $\begin{array}{l}\text { microrreticulda } \\
\text { com perfuração }\end{array}$ \\
\hline Codonanthe devosiana & médio & prolato-esfroidal & 3-cólporos & longo & circular & $\begin{array}{l}\text { microrreticulda } \\
\text { com perfuração }\end{array}$ \\
\hline Codonanthe gracilis & médio & suboblata & 3-cólporos & longo & ligeiramente lolongada & $\begin{array}{l}\text { microrreticulda } \\
\text { com perfuração }\end{array}$ \\
\hline Nematanthus brasiliensis & médio & prolato-esfroidal & 3-cólporos & muito longo & lolongada & $\begin{array}{l}\text { heterorreticulada } \\
\text { com perurações }\end{array}$ \\
\hline Nematanthus crassifolius & médio & oblato-esferoidal & 3-cólporos & longo & lalongada & $\begin{array}{l}\text { heterorreticulada } \\
\text { com perurações }\end{array}$ \\
\hline Nematanthus fissus & médio & oblato-esferoidal & 3-cólporos & longo & ligeiramente lolongada & $\begin{array}{l}\text { heterorreticulada } \\
\text { com perurações }\end{array}$ \\
\hline Nematanthus fluminensis & médio & prolato-esfroidal & 3- colpos & muito longo & --- & $\begin{array}{l}\text { heterorreticulada } \\
\text { com perurações }\end{array}$ \\
\hline Nematanthus hirtellus & médio & subprolata & 3-colpos & longo & --- & $\begin{array}{l}\text { heterorreticulada } \\
\text { com perfurações }\end{array}$ \\
\hline Paliavana prasinata & médio & subprolata & 3- cólporos & muito longo & lolongada & heterorreticulada \\
\hline Sinningia brasiliensis & médio & prolata & 3- colpos & $\begin{array}{l}\text { longo (extremidades afiladas e } \\
\text { constricção mediana) }\end{array}$ & --- & reticulada \\
\hline Sinningia bulbosa & médio & subprolata & 3- colpos & $\begin{array}{l}\text { longo com extremidades } \\
\text { afiladas }\end{array}$ & --- & $\begin{array}{l}\text { microrreticulada com } \\
\text { perfurações }\end{array}$ \\
\hline Sinningia douglasii & médio & subprolata & 3- cólporos & $\begin{array}{l}\text { longo com extremidades } \\
\text { afiladas e constricção mediana }\end{array}$ & lolongada & $\begin{array}{l}\text { microrreticulada com } \\
\text { perfurações }\end{array}$ \\
\hline Sinningia gigantifolia & médio & subolata & 3- cólporos & $\begin{array}{l}\text { longo com extremidades } \\
\text { afiladas }\end{array}$ & lalongada & $\begin{array}{l}\text { microrreticulada } \\
\text { com perfurações }\end{array}$ \\
\hline Sinningia guttata & médio & subprolata & 3- cólporos & curto com extremidades afiladas & lalongada & reticulada \\
\hline Sinningia lateritia & médio & subprolata & 3- cólporos & $\begin{array}{l}\text { longo com extremidades } \\
\text { afiladas e constricção mediana }\end{array}$ & lolongada & perfurada \\
\hline Vanhouttea calcarata & médio & prolato-esferoidal & 3- cólporos & longo com extremidades afiladas & lolongada & reticulada \\
\hline Vanhouttea lanata & médio & prolato-esferoidal & 3- cólporos & $\begin{array}{l}\text { curto com extremidades } \\
\text { afiladas e constricção mediana }\end{array}$ & lolongada & reticulada \\
\hline
\end{tabular}


Tabela 2. Medidas (em $\mu \mathrm{m})$, em vista equatorial $(\mathrm{n}=25)$ e média das medidas das aberturas ( $\mathrm{n}=10)$, dos grãos de pólen das espécies de Gesneriaceae analisadas.

\begin{tabular}{|c|c|c|c|c|c|c|c|c|c|c|c|}
\hline \multirow[t]{2}{*}{ Espécies } & \multicolumn{3}{|c|}{ Diâmetro Polar (DP) } & \multicolumn{3}{|c|}{ Diâmetro equatorial (DE) } & \multirow{2}{*}{$\begin{array}{l}\text { Forma } \\
\text { DP/DE }\end{array}$} & \multicolumn{2}{|c|}{ Colpo } & \multicolumn{2}{|c|}{ Endoabertura } \\
\hline & $\begin{array}{l}\text { Faixa de } \\
\text { variação }\end{array}$ & $\bar{x} \pm \overline{s x}$ & I.C. $95 \%$ & $\begin{array}{l}\text { Faixa de } \\
\text { Variação }\end{array}$ & $\bar{x} \pm \overline{s x}$ & I.C. $95 \%$ & & compr. & larg. & compr. & larg. \\
\hline Besleria longimucronata & $21,2-22,5$ & $22,0 \pm 0,1$ & $21,8-22,2$ & $12,5-16,2$ & $14,9 \pm 0,2$ & $14,5-15,3$ & 1,48 & 19,3 & 7,2 & --- & --- \\
\hline Besleria macahensis & $25,0-26,2$ & $25,6 \pm 0,1$ & $25,3-25,8$ & $17,5-20,0$ & $18,7 \pm 0,2$ & $18,3-19,1$ & 1,36 & 19,6 & 4,7 & --- & --- \\
\hline Besleria melancholica & $21,2-23,7$ & $22,4 \pm 0,1$ & $22,2-22,6$ & $15,0-16,2$ & $16,2 \pm 0,2$ & $15,8-16,6$ & 1,38 & 17,5 & 4,4 & --- & --- \\
\hline Besleria umbrosa & $23,7-25,0$ & $24,6 \pm 0,1$ & $24,4-24,8$ & $15,0-18,7$ & $17,1 \pm 0,1$ & $16,9-17,3$ & 1,44 & 20,2 & 7,5 & 1,3 & 1,0 \\
\hline Codonanthe carnosa & $30,0-32,5$ & $31,7 \pm 0,2$ & $31,3-32,1$ & $33,7-36,2$ & $35,6 \pm 0,2$ & $35,2-35,9$ & 0,89 & 24,4 & 8,0 & 10,7 & 8,5 \\
\hline Codonanthe devosiana & $27,5-32,5$ & $30,7 \pm 0,3$ & $30,1-31,3$ & $27,5-30,0$ & $28,0 \pm 0,2$ & $27,6-28,4$ & 1,10 & 19,1 & 5,1 & 2,2 & 2,2 \\
\hline Codonanthe gracilis & $27,5-31,2$ & $29,5 \pm 0,2$ & $29,1-29,9$ & $32,5-35,0$ & $34,1 \pm 0,2$ & $33,7-34,5$ & 0,86 & 27,2 & 5,2 & 2,2 & 2,0 \\
\hline Nematanthus brasiliensis & $26,2-30,0$ & $29,0 \pm 0,3$ & $28,4-29,6$ & $26,2-27,5$ & $27,0 \pm 0,1$ & $26,8-27,2$ & 1,07 & 28,5 & 8,0 & 8,2 & 5,2 \\
\hline Nematanthus crassifolius & $40,0-42,5$ & $41,6 \pm 0,3$ & $41,0-42,2$ & $42,5-45,0$ & $44,5 \pm 0,1$ & $44,3-44,7$ & 0,93 & 30,3 & 9,3 & 8,3 & 10,2 \\
\hline Nematanthus fissus & $35,0-40,0$ & $37,3 \pm 0,3$ & $36,7-37,9$ & $40,0-42,5$ & $41,1 \pm 0,2$ & $40,9-41,5$ & 0,90 & 30,6 & 9,3 & 4,8 & 4,0 \\
\hline Nematanthus fluminensis & $40,0-43,7$ & $41,0 \pm 0,3$ & $40,4-41,9$ & $37,5-41,2$ & $38,7 \pm 0,3$ & $38,1-39,3$ & 1,06 & 27,0 & 7,0 & ---- & ---- \\
\hline Nematanthus hirtellus & $36,2-37,5$ & $37,2+0,1$ & $37,0-37,4$ & $31,2-35,0$ & $32,8 \pm 0,2$ & $32,2-33,2$ & 1,13 & 27,0 & 4,2 & ---- & ---- \\
\hline Paliavana prasinata & $25,0-30,0$ & $26,4 \pm 0,2$ & $21,5-22,4$ & $20,0-22,5$ & $22,0 \pm 0,4$ & $25,4-27,3$ & 1,20 & 23,0 & 5,0 & 5,3 & 4,7 \\
\hline Sinningia brasiliensis & $30,0-33,7$ & $33,0 \pm 0,3$ & $32,4-33,6$ & $27,5-28,7$ & $28,9 \pm 0,1$ & $28,6-29,2$ & 1,14 & 25,5 & 4,3 & --- & --- \\
\hline Sinningia bulbosa & $28,7-31,2$ & $30,3 \pm 0,1$ & $30,0-30,6$ & $21,2-23,7$ & $22,8 \pm 0,1$ & $22,5-23,1$ & 1,33 & 25,6 & 3,8 & --- & --- \\
\hline Sinningia douglasii & $35,0-37,5$ & $36,5 \pm 0,2$ & $36,0-36,9$ & $23,7-25,0$ & $24,2 \pm 0,1$ & $23,9-24,4$ & 1,51 & 30,0 & 5,6 & 3,2 & 2,5 \\
\hline Sinningia gigantifolia & $26,2-27,5$ & $26,9 \pm 0,1$ & $26,6-27,1$ & $31,2-32,5$ & $32,1 \pm 0,1$ & $31,9-32,3$ & 0,84 & 20,3 & 5,5 & 6,2 & 7,3 \\
\hline Sinningia guttata & $31,2-32,5$ & $31,7 \pm 0,1$ & $31,5-31,9$ & $22,5-25,0$ & $24,2 \pm 0,1$ & $23,9-24,5$ & 1,31 & 19,6 & 4,7 & 9,2 & 10,2 \\
\hline Sinningia lateritia & $32,5-33,7$ & $33,3 \pm 0,1$ & $33,0-33,5$ & $27,5-28,7$ & $27,9 \pm 0,1$ & $27,6-28,1$ & 1,19 & 25,6 & 4,7 & 9,4 & 6,9 \\
\hline Vanhouttea calcarata & $30,0-32,5$ & $31,2 \pm 0,2$ & $30,8-31,6$ & $27,5-28,7$ & $28,2 \pm 0,1$ & $28,0-28,4$ & 1,11 & 20,5 & 5,4 & 9,1 & 5,4 \\
\hline Vanhouttea lanata & $27,5-30,0$ & $29,1 \pm 0,2$ & $28,7-29,5$ & $25,0-26,2$ & $26,0 \pm 0,2$ & $25,6-26,4$ & 1,12 & 17,6 & 4,6 & 7,2 & 4,2 \\
\hline
\end{tabular}

- X- média aritmética; s s--desvio padrão da média; I.C. - intervalo de confiança; compr. comprimento; larg. largura.

Tabela 3. Medidas (em $\mu \mathrm{m}$ ) dos grãos de pólen das espécies de Gesneriaceae, em vista polar: diâmetro equatorial em vista polar (DEVP); lado do apocolpo (LA); índice da área polar (IAP) e camadas da exina $(\mathrm{n}=10)$.

\begin{tabular}{|c|c|c|c|c|c|c|c|c|c|c|}
\hline \multirow[t]{2}{*}{ Espécies } & \multicolumn{2}{|c|}{ Diâmetro Equatorial } & \multicolumn{2}{|l|}{ LA } & \multirow[t]{2}{*}{ IAP } & \multicolumn{5}{|c|}{ Exina } \\
\hline & Faixa de variação & $-\mathrm{x}$ & Faixa de variação & $\overline{\mathrm{x}}$ & & total & sexina & nexina & muro & lúmen \\
\hline Besleria longimucronata* & $15,0-16,2$ & 15,5 & $6,2-7,5$ & 7,0 & 0,45 & 1,1 & 0,9 & 0,2 & -- & --- \\
\hline Besleria macahensis* & $11,2-12,5$ & 12,0 & $6,2-7,5$ & 6,6 & 0,55 & 1,7 & 1,0 & 0,7 & --- & --- \\
\hline Besleria melancholica* & $11,2-12,5$ & 12,1 & $6,2-7,5$ & 7,2 & 0,59 & 2,5 & 1,8 & 0,7 & --- & --- \\
\hline Besleria umbrosa* & $10,0-12,5$ & 11,8 & $6,2-7,5$ & 7,1 & 0,60 & 1,7 & 1,2 & 0,5 & --- & --- \\
\hline Codonanthe carnosa* & $15,0-16,2$ & 15,2 & $6,2-8,7$ & 7,6 & 0,50 & 2,0 & 1,0 & 1,0 & --- & --- \\
\hline Codonanthe devosiana* & $16,2-17,5$ & 17,0 & $3,7-5,0$ & 4,6 & 0,27 & 1,6 & 1,0 & 0,6 & --- & --- \\
\hline Codonanthe gracilis* & $18,7-20,0$ & 19,2 & $5,0-7,5$ & 5,7 & 0,29 & 2,0 & 1,3 & 0,7 & --- & --- \\
\hline Nematanthus brasiliensis & $27,5-30,0$ & 28,0 & $5,0-6,2$ & 5,2 & 0,18 & 0,8 & 1,0 & 0,9 & 0,9 & 1,7 \\
\hline Nematanthus crassifolius & $42,5-45,0$ & 43,3 & $10,0-12,5$ & 11,7 & 0,27 & 0,8 & 1,0 & 0,9 & 0,9 & 2,4 \\
\hline Nematanthus fissus & $36,2-40,0$ & 38,8 & $10,0-11,2$ & 10,0 & 0,25 & 1,0 & 1,0 & 1,1 & 1,1 & 2,3 \\
\hline Nematanthus fluminensis & $40,0-45,0$ & 42,0 & $6,7-8,7$ & 8,0 & 0,18 & 1,0 & 0,8 & 0,9 & 0,9 & 2,5 \\
\hline Nematanthus hirtellus & $25,0-25,0$ & 25,0 & $10,0-12,5$ & 11,0 & 0,44 & 1,3 & 0,7 & 0,8 & 0,8 & 1,0 \\
\hline Paliavana prasinata & $20,0-25,0$ & 24,0 & $20,0-25,0$ & 21,5 & 0,89 & 1,0 & 0,9 & 0,1 & 0,4 & 0.9 \\
\hline Sinningia brasiliensis & $16,2-18,7$ & 18,0 & $5,0-6,2$ & 5,3 & 0,29 & 2,0 & 1,0 & 1,0 & 0,6 & 1,0 \\
\hline Sinningia bulbosa & $18,7-20,0$ & 19,2 & $7,5-8,7$ & 7,8 & 0,40 & 1,7 & 1,0 & 0,7 & --- & --- \\
\hline Sinningia douglasii & $18,7-20,0$ & 19,0 & $7,5-10,0$ & 8,7 & 0,46 & 2,0 & 1,3 & 0,7 & --- & --- \\
\hline Sinningia gigantifolia* & $18,7-21,2$ & 20,0 & $6,2-7,5$ & 7,2 & 0,36 & 1,7 & 1,0 & 0,7 & --- & --- \\
\hline Sinningia guttata & $15,0-16,2$ & 15,3 & $7,5-10,0$ & 8,3 & 0,54 & 1,7 & 1,0 & 0,7 & 0,5 & 0,8 \\
\hline Sinningia lateritia* & $18,7-20,0$ & 19,5 & $6,2-7,5$ & 6,6 & 0,34 & 1,7 & 1,0 & 0,7 & --- & --- \\
\hline Vanhouttea calcarata & $15,0-16,2$ & 15,6 & $3,7-5,0$ & 4,6 & 0,30 & 1,8 & 1,0 & 0,8 & 1,0 & 2,3 \\
\hline Vanhouttea lanata & $16,2-17,5$ & 17,0 & $7,5-10,0$ & 9,0 & 0,52 & 1,7 & 1,0 & 0,7 & 1,2 & 2,5 \\
\hline
\end{tabular}

Nas espécies assinaladas com (*) não foi possível mensurar o tamanho do lúmen. 
Tabela 4. Média (em $\mu \mathrm{m}$ ) do diâmetro polar (DP) e do diâmetro equatorial (DE) dos grãos de pólen dos materiais de comparação das espécies de Gesneriaceae (n=10)

\begin{tabular}{|c|c|c|c|c|}
\hline Espécimens / Coletor & Diâmetro polar & Diâmetro equatorial & $\mathrm{P} / \mathrm{E}$ & Forma \\
\hline \multicolumn{5}{|l|}{ Besleria longimucronata } \\
\hline T.C.C. Lopes 40 & 21,8 & 15,2 & 1,42 & prolata \\
\hline G. Martinelli e J. Orleans 13467 & 22,3 & 15,5 & 1,43 & prolata \\
\hline M.C. Marques 426 & 23,0 & 17,0 & 1,34 & prolata \\
\hline \multicolumn{5}{|l|}{ Besleria macahensis } \\
\hline E. Santos 2.212, B. Faster, 1227 & 24,4 & 15,6 & 1,46 & prolata \\
\hline \multicolumn{5}{|l|}{ Besleria melancholica } \\
\hline Gruta et al. s/n (R49878) & 22,6 & 16,5 & 1,36 & prolata \\
\hline E. Pereira s/n (HB13182) & 21,9 & 15,6 & 1,40 & prolata \\
\hline E. Pereira e Duarte s/n (HB7149) & 21,9 & 16,9 & 1,29 & prolata \\
\hline \multicolumn{5}{|l|}{ Besleria umbrosa } \\
\hline Glaziou s/n (R11055) & 26,7 & 17,0 & 1,57 & prolata \\
\hline A.C.Brade $s / n$ (R20945) & 26,1 & 16,2 & 1,61 & prolata \\
\hline A. Lutz 315 & 25,7 & 16,8 & 1,52 & prolata \\
\hline \multicolumn{5}{|l|}{ Codonanthe carnosa } \\
\hline A.P. Duarte 5297 & 31,7 & 34,5 & 0,92 & oblato-esferoidal \\
\hline C.L.F.Ichaso 135 & 32,6 & 35,3 & 0,92 & oblato-esferoidal \\
\hline \multicolumn{5}{|l|}{ Codonanthe devosiana } \\
\hline Klein e Bresolin 5399 & 30,0 & 26,5 & 1,13 & prolato-esferoidal \\
\hline Konno, T. 209. & 29,0 & 25,5 & 1,14 & prolato-esferoidal \\
\hline E. Pereira 634 & 29,3 & 25,5 & 1,14 & prolato-esferoidal \\
\hline \multicolumn{5}{|l|}{ Codonanthe gracilis } \\
\hline A.P. Duarte 6239 & 26,5 & 35,2 & 0,75 & suboblata \\
\hline B.A. Moreira 18 & 27,0 & 35,2 & 0,77 & suboblata \\
\hline \multicolumn{5}{|l|}{ Nematanthus crassifolius } \\
\hline D. Araújo 3999 e N.C. Maciel & 46,4 & 41,7 & 1,11 & oblato-esferoidal \\
\hline J.M.A. Braga 524 & 38,6 & 43,7 & 0,88 & oblato-esferoidal \\
\hline \multicolumn{5}{|l|}{ Nematanthus hirtellus } \\
\hline L. Emygdio s/n (HB103948) & 40,7 & 32,2 & 1,26 & subprolata \\
\hline I.C. Santana et al. $s / n$ (HB81850) & 37,1 & 31,5 & 1,17 & subprolata \\
\hline \multicolumn{5}{|l|}{ Nematanthus fissus } \\
\hline C. Duarte 40 & 35,8 & 39,6 & 0,90 & oblato-esferoidal \\
\hline D.S. Pedrosa 1121 e H.Q. Boudet 929. & 34,9 & 40,6 & 0,86 & oblato-esferoidal \\
\hline \multicolumn{5}{|l|}{ Nematanthus fluminensis } \\
\hline C.B. Moreira 10 et al & 45,5 & 41,0 & 1,11 & prolato-esferoidal \\
\hline Z.A. Trinta 875 e E. Fromm 1951 & 44,9 & 42,4 & 1,05 & prolato-esferoidal \\
\hline C.B, Moreira 10. & 44,0 & 43,0 & 1,02 & prolato-esferoidal \\
\hline \multicolumn{5}{|l|}{ Paliavana prasinata } \\
\hline F. Pinheiro et al. 716 & 26,0 & 22,7 & 1,14 & subprolata \\
\hline F. Pinheiro 659 et al & 26,5 & 23,2 & 1,14 & subprolata \\
\hline L. Emygdio 425 & 26,0 & 21,2 & 1,23 & subprolata \\
\hline \multicolumn{5}{|l|}{ Sinningia bulbosa } \\
\hline H.F. Martins 167 & 28,7 & 22,2 & 1,29 & subprolata \\
\hline J.M.A. Braga 7102 & 29,7 & 22,8 & 1,30 & subprolata \\
\hline \multicolumn{5}{|l|}{ Sinningia douglasii } \\
\hline H.S.Irwuin et al. s/n. (HB 61590). & 34,0 & 25,5 & 1,33 & prolata \\
\hline Brade 18687 et Apparicio & 34,1 & 24,5 & 1,39 & prolata \\
\hline D. Sucre 3993 et P. I. S. Braga & 33,3 & 24,3 & 1,37 & prolata \\
\hline \multicolumn{5}{|l|}{ Sinningia gigantifolia } \\
\hline M.V.Alves 660 et al & 27,1 & 32,0 & 0,85 & suboblata \\
\hline \multicolumn{5}{|l|}{ Sinningia guttata } \\
\hline J.G. Kuhlman 6056 & 32,5 & 24,4 & 1,33 & subprolata \\
\hline D. Sucre 8825 & 32,1 & 24,5 & 1,31 & subprolata \\
\hline C. Farney 132 & 29,7 & 24,6 & 1,21 & subprolata \\
\hline
\end{tabular}



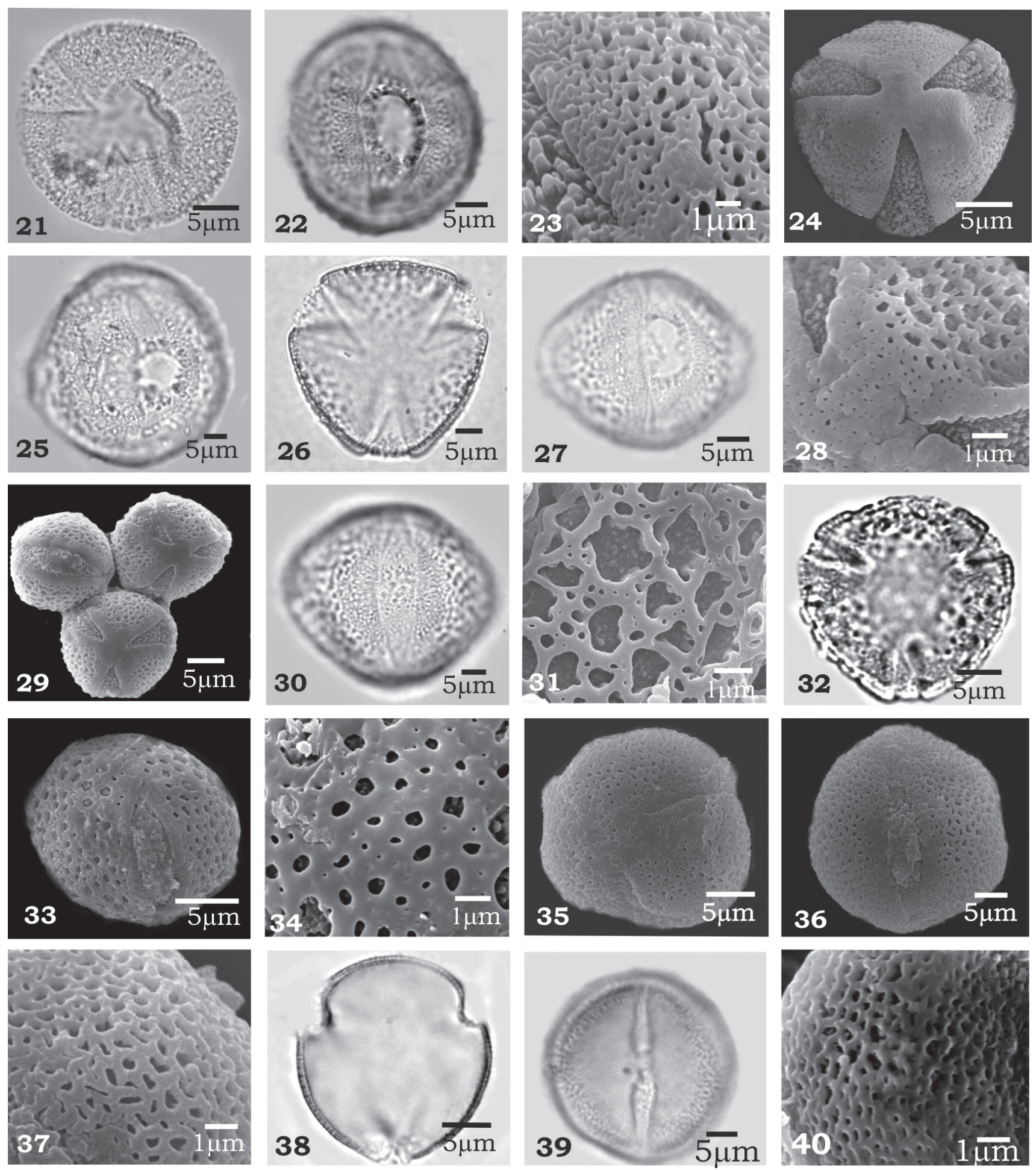

Figuras 21-40. Fotomicrografias e eletromicrografias dos grãos de pólen de Nematanthus Schrad, Paliavana Vand. e Sinningia Nees. 21-23. Nematanthus brasiliensis (Vell.) Chautems - 21. vista polar: corte óptico; 22. abertura; 23. superfície (MEV). 24-25. N. crassifolius (Schott) Wiehler - 24. vista polar (MEV); 25. abertura. 26-28. N. fissus (Vell.) L.E. Skog - 26. vista polar: corte óptico; 27. abertura; 28. superfície (MEV). 29-31. N. fluminensis (Vell.) Fritsch - 29. vista geral (MEV); 30. abertura; 31. superfície (MEV). 32-34. N. hirtellus (Schott) Wiehler - 32. vista polar: corte óptico; 33. abertura (MEV); 34. superfície (MEV). 35-37. Paliavana prasinata (Ker Gawl.) Benth. et Hook.f. - 35. vista polar (MEV); 36. vista geral (MEV); 37. superfície (MEV). 38-40. Sinningia brasiliensis (Ker Gawl.) Wiehler 38. vista polar: corte óptico; 39. vista equatorial; 40. superfície (MEV). 
Sinningia bulbosa (Ker Gawl.) Wiehler (Fig. 41-44), Sinningia douglasii (Lindl.) Chautems (Fig. 45-48), Sinningia gigantifolia Chautems (Fig. 49-50), Sinningia guttata Lindl. (Fig. 51), Sinningia lateritia (Lindl.) Chautems (Fig. 52-55)

Grãos de pólen médios, isopolares, prolatos em $S$. douglasii, suboblatos em $S$. gigantifolia, subprolatos nas demais espécies (Tab. 2), 3-colpados apenas em S. brasiliensis e S. bulbosa e 3-colporados nas demais espécies (Tab. 1), âmbito subcircular apenas em $S$. bulbosa e $S$. guttata (Fig. 41) e subtriangular nas demais espécies (Fig. 38, 52), área polar grande somente em $S$. guttata e pequena nas demais espécies (Tab. 3), superfície reticulada somente em S. guttata e microrreticulada nas demais espécies.

Abertura: 3-colporados ou 3-colpados, colpos curtos somente em $S$. guttata e longos nas demais espécies (Tab. 2). Colpos com extremidades afiladas (Fig. 39, 43, 46) e constricção mediana apenas em $S$. brasiliensis, S. douglasii (Fig. 39, 46), nas espécies colporadas a endoabertura se mostrou lalongada em $S$. gigantifolia e $S$. guttata e lolongada nas demais espécies (Tab. 1, 2). Sob MEV observa-se colpo com membrana ornamentada (Fig. 47, 50, 54).

Exina: reticulada, somente em $S$. brasiliensis e $S$. guttata, retículos formados por muros retos, estreitos e lumens pequenos (Tab. 3) (Fig. 40, 48); retículos com formas e dimensões variadas formado por muros retos, estreitos e lumens largos, que diminuem na região do apocolpo; microrreticulada com perfurações, nas demais espécies, retículos formados por muros estreitos, retos, lumens pequenos, com forma e dimensões variadas ( Tab. 3, Fig. 51); perfurada somente em S. lateritia (Fig. 55). Sob MEV verifica-se que as perfurações diminuem à medida que se aproxima da abertura e a ornamentação na região do apocolpo é quase psilada (Fig. $42,45,49)$. Sexina mais espessa que a nexina na maioria das espécies, sexina tão espessa quanto a nexina somente em S. brasiliensis (Tab. 3).

Comentários: As espécies dos gêneros Sinningia aqui analisadas sofreram diferentes tratamentos com relação à temperatura do banho-maria, de acordo com a resistência do material à saída do conteúdo citoplasmático, até se obter o resultado esperado. Sendo essas espécies pouco frequentes nos herbários consultados, poucos materiais estavam disponíveis para comparação. Os resultados mostraram que os espécimes usados para comparação, estão dentro do intervalo de confiança e fora dos limites da faixa de variação quando comparados com o respectivo material padrão (Tab. 4).

3. Vanhouttea Lem. (Fig. 56-60) - Vanhouttea calcarata Lem. (Fig. 56-58), Vanhouttea lanata Fritsch (Fig. 59-60).

Grãos de pólen médios, prolato-esferoidais, 3-colporados (Tab. 1), isopolares, âmbito subtriangular (Fig. 56), área polar pequena em $V$. calcarata e grande em V. lanata (Tab. $3)$, superfície reticulada.

Abertura: 3-colporados, colpos longos em V. calcarata e curtos em V. lanata (Tab. 2), colpos com extremidades afiladas (Fig. 58) e constricção mediana apenas em V. lanata (Fig. 59), endoabertura lolongada (Tab. 2). Sob MEV, observa-se colpo com membrana ornamentada (Fig. 58).

Exina: reticulada, retículos com muros retos, estreitos e lumens largos (Fig. 60). Sob MEV, verifica-se que os retículos vão diminuindo à medida que se aproxima da abertura $\mathrm{e}$ a ornamentação na região do apocolpo é quase psilada (Fig. 57). Sexina mais espessa que a nexina (Tab. 3).

Comentários: As espécies do gênero Vanhouttea são pouco frequentes nos herbários consultados, impossibilitando a utilização de materiais utilizados para comparação.

Chave polínica para separação das espécies de Gesneriaceae estudadas.

1. Grãos de pólen colpados

2. Grãos de pólen prolato-esferoidais, área polar muito pequena Nematanthus fluminensis

2. Grãos de pólen prolatos ou subprolatos, área polar pequena ou grande

3. Grãos de pólen prolatos

4. Área polar pequena, sexina tectado-perfurada

Besleria longimucronata

4. Área polar grande, sexina escabrada ou levemente rugulada

5. Sexina escabrada Besleria macahensis

5. Sexina levemente rugulada. Besleria melancholica

3. Grãos de pólen subprolatos

6. Sexina microrreticulada Sinningia bulbosa

6. Sexina reticulada

7. Colpos (ca. 25,5 $\mu \mathrm{m}$ ), com constricção mediana Sinningia brasiliensis

7. Colpos (ca. 27,7 $\mu \mathrm{m}$ ), sem constricção mediana Nematanthus hirtellus

1. Grãos de pólen colporados

8. Área polar muito pequena

9. Grãos de pólen prolato-esferoidais .Nematanthus brasiliensis

9. Grãos de pólen subprolatos Paliavana prasinata

8. Área polar pequena ou grande 
10. Área polar grande ( ca. $0,52-0,60 \mu \mathrm{m}$ )

11. Grãos de pólen subprolatos

Sinningia guttata

11. Grãos de pólen prolatos ou prolato-esferoidais

12. Grãos de pólen prolatos, endoabertura ligeiramente lolongada $(1,3 \times 1,0 \mu \mathrm{m})$, colpos (ca. $20,2 \mu \mathrm{m})$, sem constriccção mediana, sexina tectado-perfurada.

Besleria umbrosa

12. Grãos de pólen prolato-esferoidais, endoabertura nitidamente lolongada (7,2 x 4,2 $\mu \mathrm{m})$, colpos (ca. 17,6 $\mu \mathrm{m})$, com constricção mediana, sexina reticulada Vanhouttea lanata

10. Área polar pequena (ca. $0,27-0,36 \mu \mathrm{m})$

13. Endoabertura circular ou lalongada.

14. Endoabertura circular, grãos de pólen prolato-esferoidais Codonanthe devosiana

14. Endoabertura lalongada, grãos de pólen suboblatos ou oblato-esferoidais 15. Grãos de pólen suboblatos, sexina microrreticulada Sinningia gigantifolia 15.Grãos de pólen oblato-esferoidais, sexina heterorreticulada. Nematanthus crassifolius

13. Endoabertura lolongada

16. Endoabertura ligeiramente lolongada

17. Grãos de pólen suboblatos, sexina microrreticulada com perfurações Codonanthe gracilis

17. Grãos de pólen oblato-esferoidais, sexina heterorreticulada com perfurações. Nematanthus fissus

16. Endoabertura nitidamente lolongada

18. Grãos de pólen oblato-esferoidais ou prolato-esferoidais

19. Grãos de pólen oblato-esferoidais, sexina microrreticulada com perfurações.

19. Grãos de pólen prolato-esferoidais, sexina reticulada . Codonanthe carnosa

8. Grãos de pólen subprolatos

20. Sexina perfurada. Vanhouttea calcarata

20. Sexina microrreticulada com perfurações

Sinningia lateritia Sinningia douglasii

\section{Discussão e conclusões}

As 21 espécies estudadas palinologicamente puderam ser separadas, inicialmente, em dois grandes grupos pelo tipo de abertura (colpados e colporados). Besleria apresentou grãos de pólen, predominantemente colpados, com apenas uma espécie (B. umbrosa) apresentando grãos de pólen colporados; os gêneros Nematanthus e Sinningia apresentaram grãos de pólen colporados, exceto por duas espécies de cada gênero (N. fluminensis e N. hirtellus, S. brasiliensis e S. bulbosa); todas as espécies de Codonanthe e Vanhouttea tiveram grãos de pólen colporados.

Quanto à forma, os grãos de pólen variaram de suboblatos a prolatos. Besleria e Vanhouttea mantiveram a forma constante em todas as espécies analisadas, prolata e prolato-esferoidal, respectivamente. As espécies de Sinningia apresentaram grãos de pólen, predominantemente, subprolatos exceto pelas espécies $S$. brasiliensis (prolatos) e $S$. gigantifolia (suboblatos); os grãos de pólen das espécies dos gêneros Codonanthe e Nematanthus variaram de oblatoesferoidais a subprolatos.

Besleria e Codonanthe são os gêneros cujas espécies foram homogêneas no que diz respeito aos atributos morfopolínicos, tais como o tipo de abertura e a forma dos grãos de pólen. Apenas B. umbrosa apresentou grãos de pólen 3-colporados, ou seja, diferente da maioria das espécies do gênero; com relação ao gênero Codonanthe, além da forma e do tipo de abertura, o padrão de ornamentação da sexina também foi constante.
Em contra partida, Sinningia apresenta maior dificuldade de delimitação devido a grande variação morfológica entre as espécies, principalmente, com relação ao tipo de abertura (colpo ou cólporo), à forma que variou de subprolata a suboblata e ao padrão de ornamentação da sexina.

A maioria dos táxons analisados é endêmica à flora brasileira, com exceção de Sinningia douglasii que ocorre também a Noroeste da Argentina (Chautems \& Matsuoka 2003; Araujo et al. 2005; Lopes et al. 2005, 2007). Do elenco estudado, destacam-se seis espécies endêmicas restritas ao Estado do Rio de Janeiro: Besleria macahensis, B. melancholica, Sinningia bulbosa, S. guttata, S. lateritia e Vanhouttea lanata (Lopes et al. 2007; Chautems com. pess.). De acordo com Chautems \& Araujo (2009), S. guttata compõe o catálogo de plantas raras do Brasil; que juntamente com Vanhouttea lanata constam na lista oficial da flora brasileira ameaçada de extinção (MMA 2008).

Após o levantamento bibliográfico realizado, pode-se comprovar que dez espécies Besleria macahensis, B. melancholica, N. hirtellus, Paliavana prasinata, Sinningia bulbosa, S. guttata, S. lateritia e Vanhouttea lanata foram estudadas palinologicamente pela primeira vez no presente trabalho. Desta forma, os resultados aqui encontrados apresentam grande valor morfológico, taxonômico e sistemático, possibilitando uma melhor delimitação dos táxons analisados.

Sinningia douglasii, Nematanthus fissus e N. fluminensis também foram analisadas por Melhem \& Mauro (1973). Foram observadas diferenças com relação ao tipo de abertura e à forma dos grãos de pólen, descritos pelos 

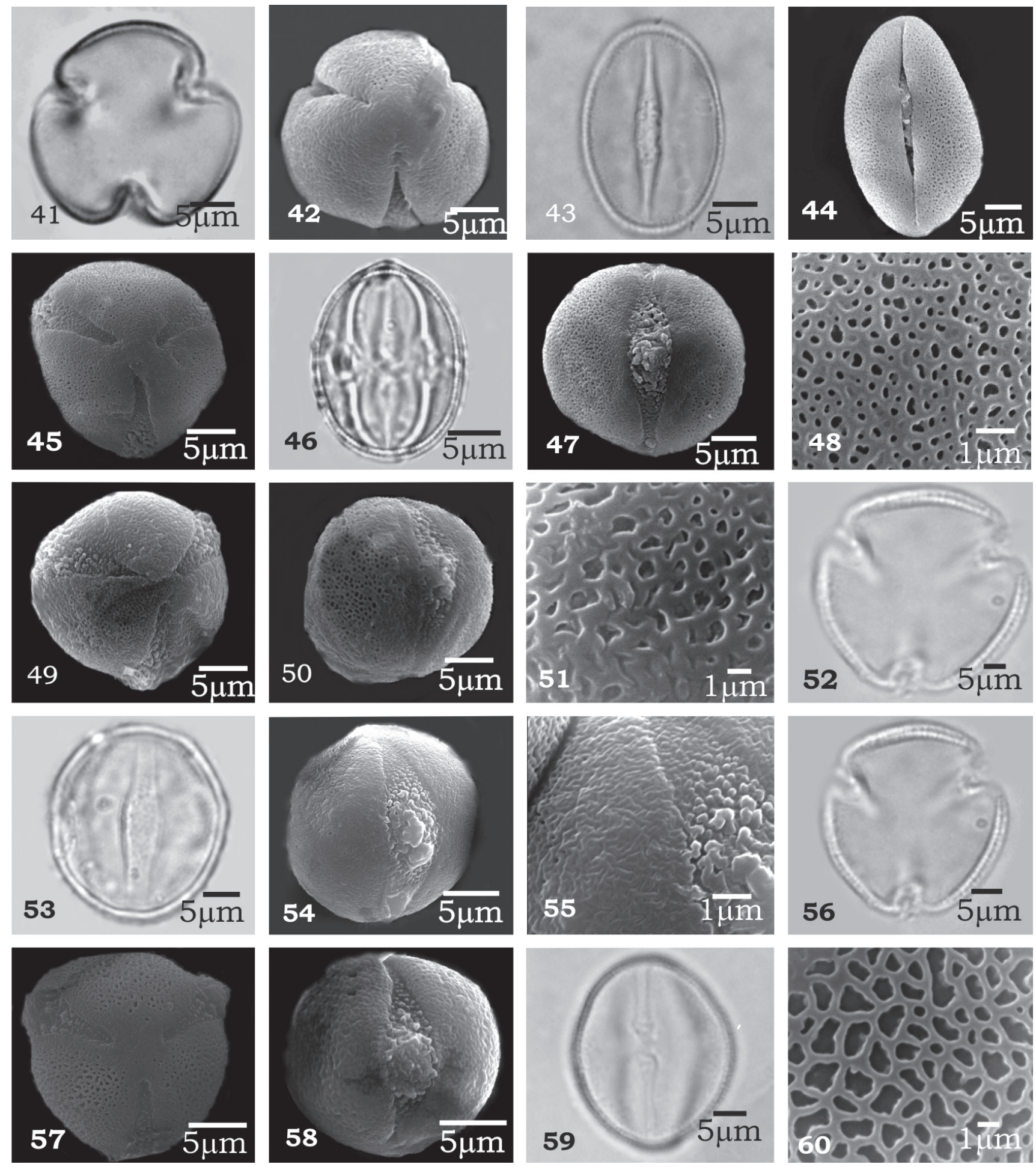

Figuras 41-60. Fotomicrografias e eletromicrografias dos grãos de pólen de Sinningia Nees e Vanhouttea Lem. 41-44. S. bulbosa (Regel \& E. Schmidt) Wiehler \& Chautems - 41. vista polar: corte óptico; 42. vista polar (MEV); 43. abertura; 44. vista geral (MEV). S. douglasii (Lindl.) Chautems - 45. vista polar (MEV); 46. vista equatorial: corte óptico; 47. vista geral (MEV); 48. superfície (MEV). S. gigantifolia Chautems - 49. vista polar (MEV); 50. vista equatorial, inclinada (MEV). S. guttata Lindl.- 51. superfície (MEV). S. lateritia (Lindl.) Chautems - 52. vista polar: corte óptico; 53. vista equatorial; 54. abertura (MEV); 55. superfície (MEV). Vanhouttea calcarata Lem. - 56. vista polar: corte óptico; 57. vista geral (MEV); 58. abertura (MEV). V. lanata Fritsch - 59. abertura; 60. superfície (MEV). 
autores como sendo colpados em $S$. douglasii, colporados e esféricos em $N$. fluminensis, prolato-esferoidais em $N$. fissus, enquanto no presente trabalho os grãos de pólen foram descritos como colpados e prolato-esferoidais em $N$. fluminensis, colporados em $S$. douglasii e oblato-esferoidais em $N$. fissus.

Espécies do gênero Codonanthe também foram analisadas por Williams (1978), os grãos de pólen foram classificados, pelo autor, com forma oblata, oblato-esferoidal, raramente prolata, enquanto no presente trabalho as três espécies de Codonanthe estudadas apresentaram forma prolato-esferoidal, suboblata e oblato-esferoidal. Os resultados encontrados pelo autor com relação à ornamentação da sexina foram, também, encontrados no presente estudo. Pode-se concluir que, o padrão de ornamentação da sexina é um importante caráter morfológico para a caracterização do gênero Codonanthe.

Filice et al. (1981) estudaram Corytholoma douglasii (Lindl.) Voss, atualmente classificada como Sinningia douglasii, espécie aqui analisada. Segundo os autores, a forma variou de prolato-esferoidal a subprolata, no presente estudo a forma variou de prolata a subprolata.

No catálogo polínico produzido por Roubik \& Moreno (1991) estavam representadas espécies de Besleria e Codonanthe. Os resultados aqui encontrados divergiram dos encontrados pelos autores com relação à forma, descrita como subprolata a esferoidal em Besleria laxiflora Benth. e com relação ao tipo de abertura descrita como colpada em Codonanthe luteola Wiehler.

Melhem et al. (2003) estudaram os gêneros Nematanthus e Sinningia. Os autores observaram grãos de pólen oblato-esferoidais, 3-colpados, sexina heterorreticulada em $N$. fornix (Vell.) Chautems. Os resultados encontrados se mostraram semelhantes para algumas das espécies de $\mathrm{Ne}$ matanthus aqui analisadas. Divergências foram encontradas nas espécies analisadas de Sinningia, quanto à forma descrita pelos autores como esférica.

Besleria, Codonanthe, Nematanthus, Sinningia e Vanhouttea foram recentemente analisados por Gasparino (2008). O autor descreveu os grãos de pólen de três espécies de Besleria e dentre elas, B. longimucronata e $B$. umbrosa considerando-as como tendo grãos de pólen oblato-esferoidais, 3-colporados e sexina rugulada em $B$. umbrosa. Os resultados aqui encontrados são semelhantes no que se refere ao tipo de abertura de B. umbrosa (colporado), mas diferem em relação à forma (prolata), ao tipo de abertura (colpado em B. longimucronata) e à ornamentação da sexina (perfurada nas duas espécies). Em Codonanthe, o autor analisou cinco espécies, das quais, três foram também aqui estudadas (C. carnosa, $C$. devosiana e $C$. gracilis) diferindo em relação à forma dos grãos de pólen e da endoabertura.

Das 19 espécies de Nematanthus analisadas palinologicamente por Gasparino (2008), quatro também o foram no presente estudo (N. brasiliensis, $N$. crassifolius, $N$. fissus e $N$. fluminensis). Foram encontradas diferenças quanto à forma dos grãos de pólen de $N$. fissus (prolato-esferoidal) e de $N$. fluminensis (oblato-esferoidal) e ao tipo de abertura de $N$. crassifolius e $N$. fluminensis (colpado). Das 35 espécies de Sinningia estudadas por Gasparino (2008), três delas (S. brasiliensis, S. douglasii e $S$. gigantifolia), além de Vanhouttea calcarata também foram analisadas aqui, tendo como única diferença, a forma do grão de pólen de Sinningia que, para o autor, foi subprolata enquanto, no presente estudo, variou: suboblata em S. gigantifolia e prolata em S. douglasii.

Pelos resultados aqui encontrados constata-se que as espécies analisadas apresentam características marcantes relacionadas à variação morfológica das aberturas e à ornamentação da sexina que permitem separar todos os táxons sendo, portanto, os atributos polínicos um importante caráter para a identificação das espécies e de grande auxílio na delimitação dos táxons, confirmando a condição de família euripalinológica definida por Erdtman (1952).

\section{Agradecimentos}

Ao Laboratório de Ultraestrutura Celular, do Instituto de Biofísica da Universidade Federal do Rio de Janeiro (UFRJ), na pessoa da técnica de microscopia eletrônica de varredura, Noêmia R. Gonçalves e ao Elivaldo Lima, técnico do Departamento de Invertebrados do Museu Nacional/UFRJ. Ao Dr. Alain Chautems, especialista em Gesneriaceae, pelas informações dos táxons ocorrentes no Estado do Rio de Janeiro. À Faperj e ao CNPq pelos auxílios à pesquisa; à CAPES pela concessão da bolsa concedida à terceira autora.

\section{Referências Bibliográficas}

Albach, D.C.; Soltis, P.S.; Soltis D.E.; Olmstead, R.G. 2001. Phylogenetic analysis of Asterids based on sequences of four genes. Annals of the Missouri Botanical Garden 88:163-212.

Angiosperm Phylogeny Group. 2009. An update of the phylogeny group classification for the orders and families of flowering plants:APG III. Botanical Journal of the Linnean Society 161(2): 105-121.

Araujo, A.O.; Souza, V.C.; Chautems, A. 2005. Gesneriaceae da Cadeia do Espinhaço de Minas Gerais, Brasil. Revista Brasileira de Botânica 28: 109-135.

Bergallo, H.G.; Rocha, C.F.D.; Alves, M.A.S.; Van Sluys, M. (eds.). 2000. A fauna ameaçada de extinção do Estado do Rio de Janeiro. Rio de Janeiro, Editora da Universidade do Estado do Rio de Janeiro.

Burtt, B.L. \& Wiehler, H. 1995. Classification of the family Gesneriaceae. Gesneriana 1: 1-4.

Chautems, A. 1988. Révision taxonomique et possibilities d' hybridations de Nematanthus Schrader (Gesneriaceae), genre endémique de la forêt côtière brésilienne. Dissertationes Botanicae 112. Berlin, J. Cramer,

Chautems, A. 1991. A família Gesneriaceae na região cacaueira da Bahia, Brasil. Revista Brasileira de Botânica 14: 51-59.

Chautems, A. \& Matsuoka, C.Y.K. 2003. Gesneriaceae. Pp. 75-103. In: Wanderley, M.G.L. et al. (eds.). Flora fanerogâmica do Estado de São Paulo. v. 3 São Paulo, Instituto de Botânica.

Chautems, A. \& Araujo A.O. 2009. Gesneriaceae. Pp. 187-190. In: Giulietti, A.M., A. Rapini, M. J.G. Andrade, L.P. Queiroz \& J.M.C. da Silva (eds.), Plantas Raras do Brasil. Belo Horizonte, Conservação Internacional - Brasil \& Universidade Estadual de Feira de Santana.

Clark, J.L.; Herenden, P.S.; Skog, L.E.; Zimmer, E.A. 2006. Phylogenetic relationships and generic boundaries in the Episcieae (Gesneriaceae) inferred from nuclear, chloroplast and morphological data. Táxon 55: 313-336.

Erdtman, G. 1952. Pollen morphology and plant taxonomy Angiosperms an introduction to palynology. 2 ed. Stockholm, Almquist \& Wikseus. 
Felice, M.A.C., Sanchis, A.M. \& Villar, L.M. 1981. Granos de pólen de las Gesneriaceae de la Argentina. Cominicaciones del Museo Argentino de Ciencias Naturales. Bernardino Rivadavia 2: 77-89.

Fritze, K.J. \& Williams N.H. 1988. The taxonomic significance of pollen morphology in the Columnea alliance (Gesneriaceae: Gesnerioideae). Annals of the Missouri Botanical Garden 75: 168-191.

Gasparino, E.C. 2008. Palinotaxonomia de espécies brasileiras de Gesneriaceae, com ênfase nas ocorrentes no Estado de São Paulo. Tese (Doutorado em Biodiversidade vegetal e meio ambiente). Instituto de Biociências, Universidade de São Paulo.

Holmgren, P.K.; Holmgren, N.H.; Barnett, L.C. 1990. Index herbariorium Part 1: The herbaria of the world. 8 ed. New York, New York Botanical Garden.

Lopes, T.C.C.; Chautems, A.; Andreata, R.H.P. 2005. Diversidade florística das Gesneriaceae na Reserva Rio das Pedras, Mangaratiba, Rio de Janeiro, Brasil. Pesquisas, Botânica 56: 75-102.

Lopes, T.C.C.; Andreata, R.H.P. \& Chautems, A. 2007. Distribuição e conservação do gênero Besleria L. (Gesneriaceae) no Brasil: dados preliminares. Revista Brasileira de Biociências 5: 876-878.

Melhem, T.S. \& Mauro, C. 1973. Pollen Morphologycal studies in Gesneriaceae. Hoehnea 2: 13-27.

Melhem, T.S.; Cruz-Barros, M. A. V.; Corrêa, A.M.S.; Makino-Watanabe, H.; Silvestre-Capelato, M. S.; Esteves, V. L. G. 2003. Variabilidade polínica em plantas de Campos do Jordão (São Paulo, Brasil). Boletim do Instituto de Botânica 16: 16-104.

MMA, 2008. Lista Oficial das Espécies da Flora Brasileira Ameaçadas de Extinção. Disponível em: http://www.mma.gov.br (Acesso em: $15 / 11 / 2009$ ).

Perret, M.; Chautems A.; Spichiger R.; Kite G.; Savolainen, V. 2003. Systematic and evolution of tribe Sinnigieae (Gesneriaceae): evidence from phylogenetic analyses of six plastid DNA regions and nuclear $n c p \mathrm{GS}$. American Journal of Botany 90: 445-460.
Punt, W., Blackmore, S., Nilsson, S. \& Le Thomas, A. 2007. Glossary of pollen and spore terminology. Review of Paleobotany and Palynology 143: $1-81$.

Rocha, C.F.D. da; Bergallo, H.G.; Alves, M.A.S.; Van Sluys, M. 2003. A biodiversidade nos grandes remanescentes florestais do Estado do Rio de Janeiro e nas restingas da Mata Atlântica. RiMa, São Carlos.160p.

Roubik, D.W. \& Moreno, J.E. 1991. Pollen and spores of Barro Colorado Island. Missouri Botanical Garden, New York. 268 p.

Salgado-Labouriau, M.L. 1973. Contribuição à Palinologia dos Cerrados. Rio de Janeiro, Academia Brasileira de Ciências.

Skog, L.E. \& Boggan. J.K. 2007. World Checklist of Gesneriaceae. Washington, DC: Dept. of Botany, Smithsonian Institution. http:// botany.si.edu/Gesneriaceae/Checklist (Acesso em: 16/06/2008).

Smith, J.F. 1996. Tribal relationships within Gesneriaceae: a cladistic analysis of morphological data. Systematic Botany 21: 497-513.

Smith, J.F. 2000. A phylogenetic analysis of tribes Beslerieae and Napeantheae (Gesneriaceae) and evolution of fruit types: parsimony and maximum likelihood analyses of $n d h F$ sequences. Systematic Botany 25: 72-81.

Smith, J.F; Wolfram J.C.; Brown, K.D.; Carroll, C.L.; Denton, D.S. 1997. Tribal relationships in the Gesneriaceae: evidence from DNA sequences of the chloroplast genes $n d h \mathrm{~F}$. Annals of the Missouri Botanical Garden 84: 50-66.

Wiehler, H. 1983. A synopsis of the neotropical Gesneriaceae. Selbyana 6: $1-219$.

Williams, N. H. 1978. Pollen structure and systematics of the neotropical Gesneriaceae. Selbyana 3: 310-322.

Zimmer, E.A.; Roalson, E.H.; Skog, L.E.; Boggan, J. K. \& Idnurm, A. 2002. Phylogenetic relationships in the Gesnerioideae (Gesneriaceae) based on nrDNA ITS and cpDNA trnL-F and trnE-T spacer region sequences. American Journal of Botany 89: 296-311. 